\title{
The use of the ash of thermal power plants for the production of efficient porous insulation
}

\author{
Anatoliy Pavlenko', Hanna Koshlak², and Anna Maria Slowak,* \\ ${ }^{1}$ Faculty of Environmental, Geomatic and Energy Engineering, Kielce University of Technology, Poland. \\ ${ }^{2}$ Ivano-Frankivsk National Technical University of Oil and Gas, Ukraine
}

\begin{abstract}
The article presents the results of research related to the use of ash from thermal power plants for the production of porous heat insulating materials. Using the method of differential - thermal analysis, the optimal values of the composition of the raw mix and the thermal regimes of the formation of the porous structure were found. It is shown that it is possible to obtain a new ash-based binder and thus replace up to $70 \%$ of cement in the production of thermal insulation. The properties of the new material are similar to the properties of foam concrete.
\end{abstract}

\section{Introduction}

The impact of thermal power plants (TPP) on the environment depends largely on the type of fuel. Coal is most polluted of all energy sources and making the largest contribution to global climate change. In coal power plants account for the biggest share of greenhouse gas emissions in the energy sector, as they have the highest rate of release of carbon dioxide per unit of electricity produced compared with all other fossil fuels. When burning coal into the atmosphere large quantities of solid particles containing not burned carbon oxides and heavy metals emitted as carbon monoxide (CO) and toxic organic compounds, including dioxins and benzopyrene, have carcinogenic effect, , fly ash, sulfur and sulfuric anhydride, nitrogen oxides, some amount of fluoride and gaseous products of incomplete combustion. So especially harmful condensation power plants working on low-grade fuels. Among these stations applies Burshtyn TPP.

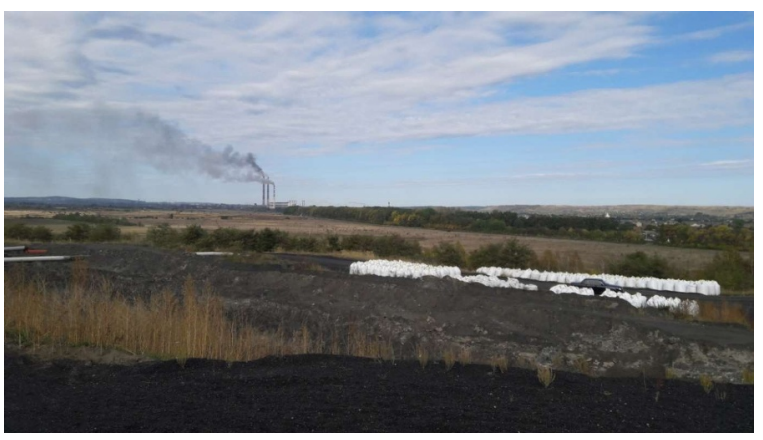

Fig. 1. Burshtyn TPP (ash storage №3)

\footnotetext{
*Corresponding author: anmarii@windowslive.com
}

Solid waste production BTPP is the main fuel slag and ash. Laboratory studies show that in 2015 was formed 526,335 tons of ash and 125,583 tons of slag, which in large near BTPP form parts of ash dumps (Fig. 1).

Most European TPP do not form ash dumps because their rational use, given the content of the ash, useful for technologies manufacturing of building material chemical elements.

\section{Analysis of recent sources research and publications}

The publications [1-10] shows the advantages of using high-calcium ash in the production of cellular concrete. The use of ashes in the production of cellular concrete in reality presented in various versions, from using it as a main component to the introduction of ash in the raw material as an additive. Since the high-calcium ash has all the source characteristics of materials for the production of cellular concrete (dispersion and binder potential) to the same cellular structure softens degradation expansion ash pore space without developing cracks.

The main barrier using ash as a raw material for the production of building materials is its content of free calcium and magnesium oxides in a state of burnout. Other impediment - is the wide range the composition of highly-calcium ash defining significant fluctuations in the properties (strength, medium density, frost resistance, etc.) of the finished material.

According to literature data, it was found that neutralize the negative impact of $\mathrm{CaO}$ ash possible in different ways: physical, chemical, and by sharing with cement or other "diluents."

For the production of high-quality non-autoclave gas concrete, complex and energy-intensive solutions should be used: 
- Constantly changing technological modes in accordance with fluctuations in the properties of ash. Thus, in [2] established the optimum mixing time ash and water mass, depending on the timing of grasp the - All the researchers recommend the use of compulsory steaming and grind in some decisions of high-calcium ash [3] or drying of products [4].

At the same time, some researchers are concerned with the question the use of high-calcium ash for the production of cellular concrete, not only take into account the factor of variability of composition and properties of the ash. Therefore, developed technology, ash gas concrete are characterized by a significant percentage of defective products due to variations in the properties of finished products, and other problems. The latter is often impossible to organize a sustainable manufacturing process using raw materials with a large variation of its composition and properties without correction (composition mass, technological processes parameters, etc.). In addition, the proposed technology is almost impossible to use in small production.

Therefore it is necessary to develop such schemes, the production of non-autoclaved gas concrete based on high-calcium ash TPP that will provide a stable material with high construction and technical properties on technology that does not require steaming, grind and other difficult-to-small enterprises process stages.

You should also explore the possibility of obtaining materials with different structures, for example with a porous structure. These materials can be analogs of foam concrete or porous insulation materials.

\section{Emphasis previously unsolved parts of the general problem}

For production non-autoclave cellular concrete, including small enterprises - the most rapidly developing sector of wall materials today. Classical technology of these concrete is based mostly on cement and sand unground. The use of ash TPP for cellular concrete recommended by the majority of regulatory documents. The greatest effect is achieved by using high-calcium ash.

All the previous decisions on the development of technologies of non-autoclaved aerated concrete based on high-calcium ash TPP on coal were sent to the maximum of their introduction to the raw mixture. This resulted in unnecessarily complex and energy-intensive technologies (permanent change dosages and technological modes in accordance with fluctuations in the properties of ash, mandatory steaming, and some decisions grind components or drying products). All this did not allow to widely implement the proposed technology, especially in small enterprises. Therefore, it required the development of non-autoclave gas concrete technology based on high-calcium ash TPP gives the material with consistently high construction and technical properties on technology that does not require steaming, grind and other complex for small productions process stages.
Changes in the thermal regimes of processing materials containing ash can also ensure the formation of a porous structure. The replacement of cement with ashes makes it possible to also get foam concrete. But to achieve the necessary physical properties of this product, you need to adjust the composition of the initial mixture. This of course required additional research.

In our earlier studies $[5,6]$, we changed the structure of the material using thermal modes of processing the raw mix and selecting its rational composition. And thus it was possible to get a new porous material that can serve as thermal insulation.

\section{Problem statement}

The purpose of this work is to study the possibility of replacing cement with the ash of the Burshtyn TPP in technologies for producing concrete products, foam concrete and the production of porous insulation material.

We set the goal of our research to find a rational composition of the raw mix for the production of efficient concrete, foam concrete and porous materials with the maximum possible replacement of cement with ash.

The main indicator of porous insulation is thermal conductivity. Therefore, this paper also aims to develop a method for evaluating this indicator for new porous materials.

\section{Research results. Influence of ash components on structure formation processes}

Due to the content in the study ash of basic oxides $\left(\mathrm{SiO}_{2}\right.$, $\mathrm{Al}_{2} \mathrm{O}_{3}, \mathrm{Fe}_{2} \mathrm{O}_{3}, \mathrm{CaO}, \mathrm{MgO}, \mathrm{K}_{2} \mathrm{O}$ ) it can be attributed to the high-calcium mineral resources, which typically use a raw mixture before thermal swelling in the production of TPM. A result we get a solid porous materials [9-12].

The use of ash in pure form in building materials compounded by the negative impact of calcium oxide, which is present in free form in a state of burnout.

Hydration of $\mathrm{CaO}$ particles, often covered with a vitreous shell leading to cracking and fracture of hardened material. Neutralize the negative impact of $\mathrm{CaO}$, perhaps in different ways: physical, chemical, and by sharing with cement. The positive effect of in the latter case will occur both due to dilution effect and deterrent effect of destructive phenomena solid cement stone. In our work we use both methods. Since calcium oxide in the ash BTPP not much, each of the methods may be appropriate. The most widely, to eliminate the destructive effects of ash are hardening additive calcium chloride or other chlorides. In our technology for the production of porous concrete to intensify the gassing requires the presence of alkali $\mathrm{NaOH}$, which can be synthesized as a result exchange reactions (alkali in our technology can be added to the raw material mixture as a separate component). 
It is possible also to its gradual formation of ash elements BTPP, which would control chemical transformations in the raw mixture in step swelling. New dual compound promote rapid formation of a mixture of plasticity and its early hardening. These properties can be the basis of the controlled process of forming a given structure, which is the aim of this study.

Therefore in the interaction these chemical elements, accelerated hydration $\mathrm{CaO}$ and accelerated the process of formation hydrates mixture.

When interacting with lime in the presence of aluminum phases of Portland cement clinker and ash, the reaction to form the hydro-sulfo aluminate and hydrochlor- aluminate of calcium:

$$
\begin{aligned}
& n \mathrm{CaO}+\mathrm{Ca}_{3}\left(\mathrm{AlO}_{3}\right)_{2}+2 n \mathrm{NaCl}+(\mathrm{m}+1) \mathrm{H}_{2} \mathrm{O} \rightarrow \\
& \rightarrow 3 \mathrm{Ca}_{3}\left(\mathrm{AlO}_{3}\right)_{2} \cdot n \mathrm{CaCl} l_{2} \cdot \mathrm{mH}_{2} \mathrm{O}+2 \mathrm{nNaOH} \\
& n \mathrm{CaO}+\mathrm{Ca}_{3}\left(\mathrm{AlO}_{3}\right)_{2}+2 \mathrm{Na}_{2} \mathrm{SO}_{4}+(m+1) \mathrm{H}_{2} \mathrm{O} \rightarrow \\
& \rightarrow 3 \mathrm{Ca}_{3}\left(\mathrm{AlO}_{3}\right)_{2} \cdot n \mathrm{CaSO} \mathrm{OH}_{4} \cdot \mathrm{mH}_{2} \mathrm{O}+2 n \mathrm{NaOH}
\end{aligned}
$$

It will accelerate the hydration of $\mathrm{CaO}$ and ash released alkaline solution $\mathrm{NaOH}$.

As a result exchange reactions that occur between sodium sulphate and cement hydration products formed additional quantity of gypsum and alkali $\mathrm{NaOH}$ (reaction (2)). Then $\mathrm{NaOH}$ easy carbonization by carbon dioxide that enters the solution from the air by the reaction:

$$
2 \mathrm{NaOH}+\mathrm{H}_{2} \mathrm{CO}_{3} \rightarrow \mathrm{Na}_{2} \mathrm{CO}_{3}+2 \mathrm{H}_{2} \mathrm{O}
$$

Sodium carbonate is primarily interacts with gypsum, as it is most soluble product of cement hydration and under the influence of $\mathrm{NaOH}$, it significantly increased solubility:

$$
\mathrm{CaSO}_{4} \cdot 2 \mathrm{H}_{2} \mathrm{O}+\mathrm{Na}_{2} \mathrm{CO}_{3} \rightarrow \mathrm{CaCO}_{3}+\mathrm{Na}_{2} \mathrm{SO}_{4}+\mathrm{aq}
$$

Is well soluble sodium sulfate again reacts with calcium oxide to form gypsum and alkali (2). Reactions $\mathrm{Eq}(2)$ and $\mathrm{Eq}(3)$ intermediate and $\mathrm{Eq}(4)$ main.

Because of the fact that Burshtyn ash contains up to $61 \%$ aluminosilicate glass phase in the ash-cement compositions will be similar to the reaction between with sodium sulfate. This is certainly a positive moment, since in theory we have the ability to influence the kinetic parameters of swelling. Also, carbonated shrinkage that occurs during the use of products will partly compensate for their expansion deformation due to quenching of free lime.

In the DTA curves hydrated mixture based on fly ash, Portland cement, silicate recorded four endothermic effects, accompanied by a decrease in weight (Fig. 2).

All endo-effects, as the differential - thermal analysis associated with weight loss in a wide temperature range. Significant endo-effect occurs at temperatures $50-250{ }^{\circ} \mathrm{C}$ extremes of from $115{ }^{\circ} \mathrm{C}$ to $123{ }^{\circ} \mathrm{C}$ and is associated with the removal of adsorbed water with helium-like hydration products, such as calcium hydrosilicates type CSH (I), as well as water of crystallization of hydrosulfo-aluminate of calcium AFt - phase.

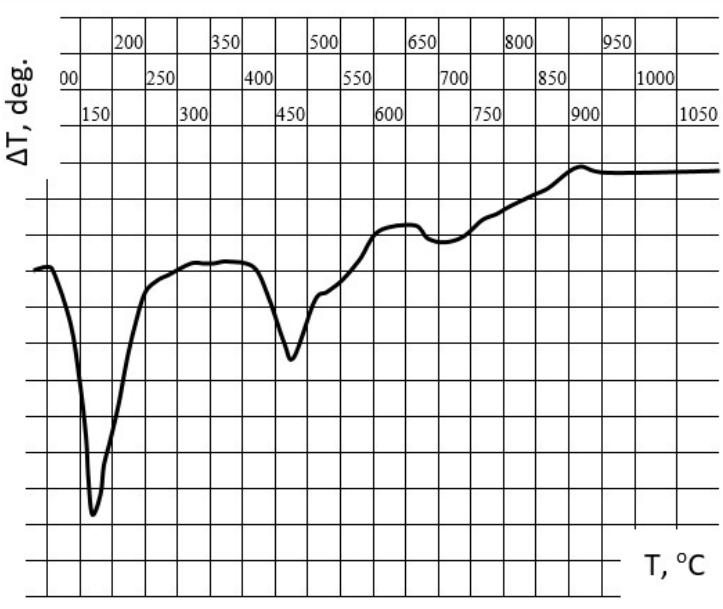

Fig. 2. DTA raw mix with the addition of $70 \mathrm{wt}$. parts of BTPP ash and 5 wt. parts of Portland cement M100 and 15 wt. parts sand pieces

A clear endothermic effect is observed in the temperature range $370-420{ }^{\circ} \mathrm{C}$ and describes the process of dehydration of calcium hydroxide scheme: $\mathrm{Ca}(\mathrm{OH})_{2} \rightarrow \mathrm{CaO}+\mathrm{H}_{2} \mathrm{O}$.

The small endo-effects at 652 and $780{ }^{\circ} \mathrm{C}$ associated with the processes of decomposition hydrosilicates calcium (CSH (II)) and calcination calcite. At temperatures of about $930^{\circ} \mathrm{C}$, small exo-effect is caused by crystallization tobermo-barito-like gel in wollastonite.

Since the swelling and the formation of structural strength aerated concrete array depend significantly on water-solid ratio (WSR), the first stage searched the optimal amount of water for mixing in ash-cement gas concrete compositions.

For the purpose of determine the effect of water-solid ratio on swelling aerated concrete, aerated concrete mixtures were manufactured with WSR in the range of 0.2 to 0.6 . In this case, aerated concrete mixture made based on cement and sand or based on cement and ash Burshtyn TPP (in the ratio from $100 \times 0$ to $30 \times 70$ ) using chemical additives.

The mixture was prepared as follows: samples of ash and sand mixed with water at a temperature of $20-30$ ${ }^{\circ} \mathrm{C}$, added cement and stirred for 2 minutes. Further, in each test was injected the same number of aluminum suspension of the calculation of obtaining the average density of aerated concrete $700 \mathrm{~kg} / \mathrm{m}^{3}$, stirred for a further 1 minute and poured in volumetric capacity, which was swelling the mixture at an ambient temperature of $20{ }^{\circ} \mathrm{C}$. After the complete swelling mixture controlled its height as a percentage of the height of the fill. Then found the perfect amount of water and chemical additives to the maximum height of swelling. The results are presented in Table 1.

Researches have shown that the studied range with increasing WSR height of expanded cement-sand aerated concrete increases. For ash-cement aerated concrete is the optimum ratio for WSR, which is 0.5 . With the use of chemical additives $\mathrm{NaCl}$ and $\mathrm{Na}_{2} \mathrm{SO}_{4}$ amount of water does not change except for warehouses in which these additives are used in small amounts $(0.5 \%)$. In our 
studies, we varied the amount of $\mathrm{NaCl}$ and $\mathrm{Na}_{2} \mathrm{SO}_{4}$ from 0 to $5 \%$. Table 1 shows the optimal ratios of these additives. The number of repetitions of all measurements - 6. Decrease WSR in this case is probably due to "dilution" mixture through peptization effect of fine particles that can get aerated concrete with uniform porosity with less water. But the additives do not affect the process of swelling as a dry ash (it prolonged storage) by chemical reactions, these compounds are formed, and adding or increasing their number does not change the quantitative results of this process (as seen also from Table 1).

The use of Burshtyn ash instead of sand can increase the height of the swelling by $70 \%$ and the use of chemical additives - an additional 3 to $7 \%$ due to the intensification of processes of gas emission as a result of the gradual formation of $\mathrm{NaOH}$ in exchange reactions, which activates processes gassing.

Table 1. Effect of PTS on percentage swelling of concrete (\%)

\begin{tabular}{|c|c|c|c|c|c|}
\hline \multirow[t]{2}{*}{ Mix } & \multicolumn{5}{|c|}{ WSR } \\
\hline & 0,2 & 0,3 & 0,4 & 0,5 & 0,6 \\
\hline Cement + Sand & 120 & 195 & 220 & 225 & 225 \\
\hline Cement + Ash & 200 & 280 & 350 & 370 & 360 \\
\hline $\begin{array}{l}\text { Cement } \\
+\mathrm{Na}_{2} \mathrm{SO}_{4}, 1 \%\end{array}$ & 200 & 290 & 350 & 376 & 370 \\
\hline $\begin{array}{l}\text { Cement } \\
+\mathrm{Na}_{2} \mathrm{SO}_{4}, 2 \%\end{array}$ & 205 & 290 & 355 & 380 & 380 \\
\hline $\begin{array}{ll}\text { Cement } & + \text { Ash } \\
+\mathrm{NaCl}, 1 \% & \end{array}$ & 210 & 295 & 370 & 385 & 380 \\
\hline $\begin{array}{ll}\text { Cement } & + \text { Ash } \\
+\mathrm{NaCl}, 2 \% & \end{array}$ & 205 & 295 & 370 & 390 & 370 \\
\hline
\end{tabular}

The use of chemical additives can reduce the terms of hardening concrete mass as they provide fast water binding and accumulation of solid phase with maximum density filling space frame. In our opinion this is achieved through additional intensive synthesis and $\mathrm{AFt}$ AFm phases associated increased amount of $\mathrm{H}_{2} \mathrm{O}$, with a high growth rate and ensure the quick formation of structural strength.

Increasing the WSR, more than 0.5 leads to the separation of the initial mixture to form large cavities with a diameter of $2 \mathrm{~cm}$. This is usually due to swelling induction processes and prehension gas. In addition, the increase in WSR promoted extension of swelling and prehension of gas mass since it was accompanied by a decrease in the limiting stress and shear under plastic strength of porous concrete. The introduction of additional quantities of water reduces the strength of concrete, increase their deformation and final moisture content of the material.

The main properties of gas-concrete mixtures directly dependent on the rheology-ash cement and cement-sand aerated concrete. Under the influence of physical and chemical processes occurring in the interaction of cement, coal ash BTPP and water, rheological properties of such mixtures vary. Changes viscosity and maximum stress displacement increases strength plastic systems. The degree of change rheological characteristics depend on the type of raw mixture aerated, water-solid ratio and additives used. From the velocity structure formation gas concrete mixtures depends time of stay in array form. Therefore, the study of rheological characteristics of such systems is an urgent task.

For determination of strength of aerated concrete have been selected compositions with the largest percentage of swelling (Table. 1). The results are presented in Fig. 3. Slow structure formation, apparently a slow set of structural strength and increase shrinkage, has a classic cement-sand aerated concrete. It is characterized by slow growth strength, which is to end grasp cement (4 hours) $0.8 \mathrm{~Pa}$, and in 10 hours - a total of $1.8 \mathrm{~Pa}$, while for subsequent technological processes an array of aerated concrete should be $2.50-3.0 \mathrm{~Pa}$.

For ash-cement aerated concrete typical slow rate of recruitment strength, even after 10 hours you can perform various operations that provides technology for manufacturing gas concrete structures. It should be noted that after 1 day strength of cement-ash aerated concrete is higher on average $50-70 \%$.

\section{Thermal insulation materials with high-porous structure based on technogenic mineral fillers}

The study performed is aimed at the search and development of an optimized raw material mixture variant of the silicon oxide containing technogenic component: fly ash of thermal power plants and methods of obtaining the fly ash based porous alkaline-silicate composite thermal insulating materials of extended application, differing from the analogues by their composition, the content of the starting raw mass, the sequence and modes of the target product formation, the applied technological equipment.

\section{Research methodology}

In the present project, the set task of making the targeted porous thermal insulating material is achieved by means of the raw mass hot foaming technology, which procedure includes the four main stages:

1) preparation of the starting raw mixture components and homogenization of the latter;

2) the composite system "gaging" by soluble glass and formation of a persistent gel; fragmentation of the hardened raw mass and placement of the granulate into lined dismountable molds;

3) heating and transferring of the workpieces' substance into the pyroplastic state $\left(110-115^{\circ} \mathrm{C}\right)$;

4) further hot foaming and reproduction of the regular porous macrostructure of composite systems (130$220^{\circ} \mathrm{C}$ ) and formation of the targeted processed product's properties $\left(500-550^{\circ} \mathrm{C}\right)$.

The blowing agent in this case is water (mainly silanol or molecular, strongly bound by hydrogen bonds 
with unbridged oxygen atoms), which is released during heat treatment of composite systems.In the raw mixture, the industrial soluble glass, thermal power plants fly ash of the mixed chemical composition (see Table 2), sticky portland cement and, additionally, a thickener (prestaged partially dehydrated hardened "dry glass") are used.

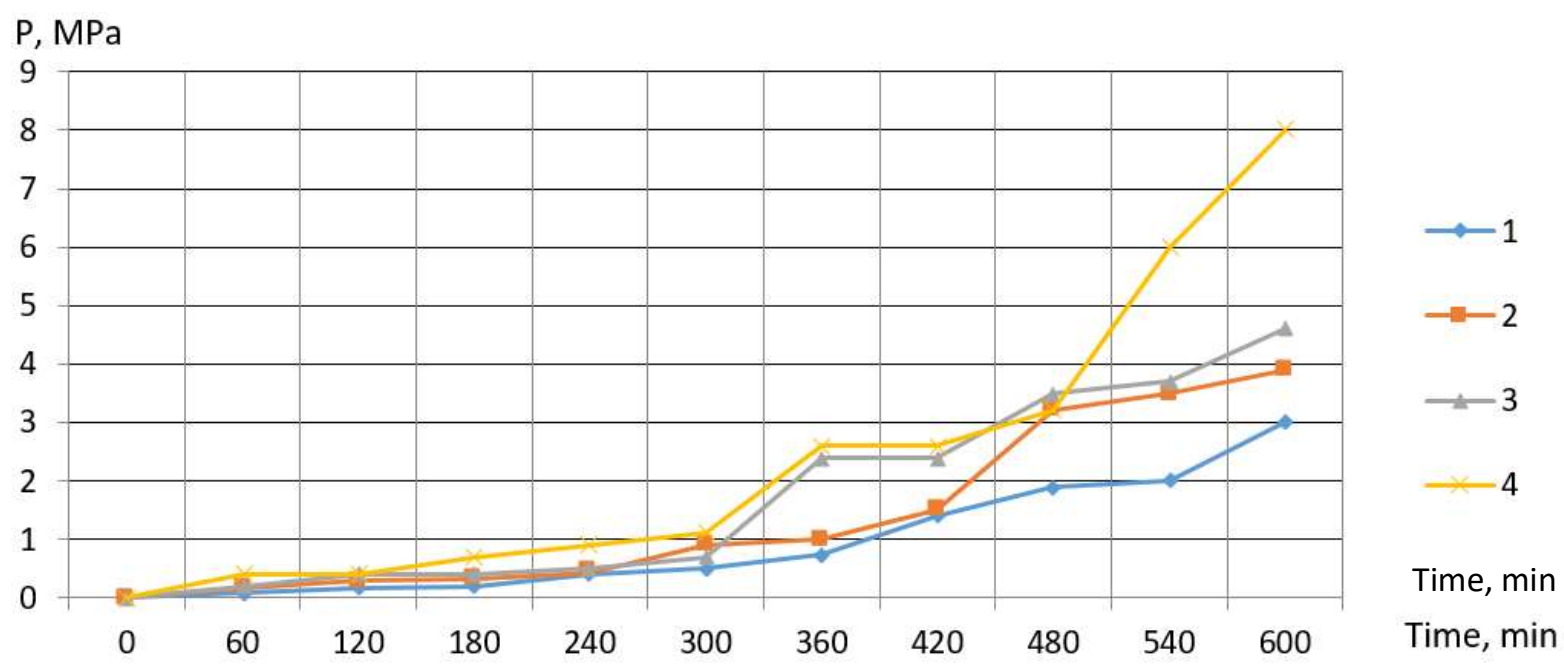

Fig. 3. The strength of the aerated concrete arrays, depending on the type of raw material mixture: 1 - cement-sand aerated concrete ; 2 - cement-ash aerated concrete; 3 - cement-ash aerated concrete with the addition of sodium sulphate (1\%); 4 - cement-ash aerated concrete with the addition of sodium chloride (1\%).

Table 2. Chemical composition of the thermal power plants fly ash, mass. \%

\begin{tabular}{|l|l|l|l|l|l|l|l|l|l|l|l|}
\hline $\begin{array}{c}\text { Ash } \\
\text { componen } \\
\text { ts }\end{array}$ & $\mathrm{SiO}_{2}$ & $\mathrm{Al}_{2} \mathrm{O}_{3}$ & $\mathrm{Fe}_{2} \mathrm{O}_{3}$ & $\mathrm{MgO}$ & $\mathrm{CaO}$ & $\mathrm{Na}_{2} \mathrm{O}$ & $\mathrm{K}_{2} \mathrm{O}$ & $\mathrm{Mn}_{3} \mathrm{O}_{4}$ & $\mathrm{TiO}_{2}$ & $\mathrm{SO}_{3}$ & $\mathrm{P}_{2} \mathrm{O}_{5}$ \\
\hline $\begin{array}{l}\text { Amount, } \\
\%\end{array}$ & 51.68 & 16.75 & 14.47 & 0.88 & 4.38 & 0.35 & 2.58 & 0.04 & 0.86 & 4.24 & 0.49 \\
\hline
\end{tabular}

In the prepared samples, the fly ash is manifesting good reinforcing properties, high thermal stability, sufficient resistance to aggressive media, has a small bulk density. At the same time, the results of the authors' studies [9] (on the ability of alkaline-silicate systems with $\mathrm{Al}_{2} \mathrm{O}_{3}$ in alkaline media to form insoluble products of $\mathrm{Na}_{2} \mathrm{O} \cdot \mathrm{Al}_{2} \mathrm{O}_{3} \cdot 2 \mathrm{Si}_{2} \mathrm{O}_{3} \cdot \mathrm{nH}_{2} \mathrm{O}$ ) permit to consider aluminum oxide contained in ash to be a modifying component that provides the raw mix with the properties necessary for the targeted product formation.

The "setting" rate control of the suggested raw mix during the formation of hydrosilicic acid xerogel (depending on the executed tasks purposes) was performed by means of varying properties of the thickener used and by means of regulating the hardened processed mass fragmentation in the further processes and its subsequent hot foaming.

The raw mix prepared according to the optimized formulation, in contrast to the previously considered analogues, starts hardening at the usual temperature from the moment of its "gaging" with soluble glass and forms a plastic cake with the properties necessary for further fragmentation.

The suggested raw mix also permits to overcome the difficulties associated with drying of viscous rare-glass mix to remove a large output amount of water $(56-62$ $\%)$ to the water content of $33-38 \%$ needed to obtain a rigid hydrogel capable of thermal blowing.
The optimized formulation of the raw mix allows processing of the compositions in various ways, with the formation of thermal insulating materials of extended application. An important prerequisite for their reproduction with the necessary properties system is strict compliance with the regulatory requirements established by the previous empirical studies.

In parallel with the formulation development, the technology of samples manufacturing was being tried. Thereat, the decisive factor the exclusion of the raw mix granulation stage after heat treatment $110-115^{\circ} \mathrm{C}$ and the use of sealed closed forms at their temperature annealing.

The suggested hot air entrainment of the silicate compositions structure "blowing" of the systems in a xerogel form passes quickly, avoiding the viscousadhesive state. The determining factor in the process of the systems thermal activation was the technical performing of their heating reproduced rate.

The conscious choice of its optimal mode is motivated by empirical data to determine the thermal foaming features of composite systems obtained by the method of differential-thermal analysis (DTA) presented in Fig.4. 


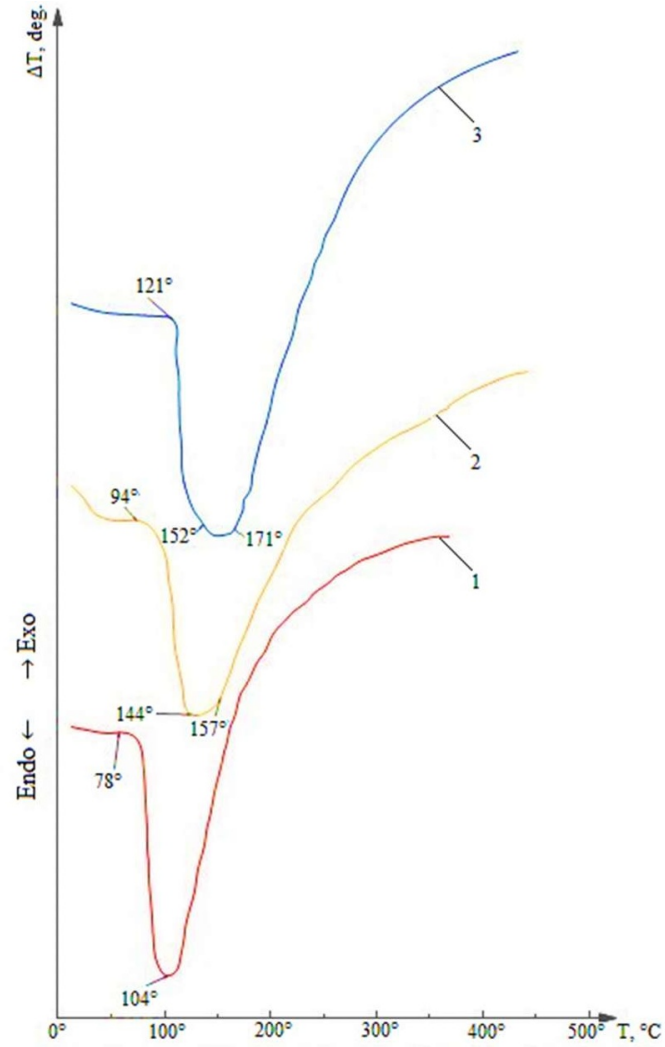

Fig. 4. DTA thermograms of sodium rare-glass composites xerogels in coordinates $\Delta \mathrm{T}-\mathrm{T}$, recorded at heating the samples in adequate conditions at different rates:

curve $1-4$ deg. / min.; curve $2-7$ deg. / min.; curve $3-20 \mathrm{deg}$. / min.

The air entrainment process includes the three main stages, the duration and nature of which depends on the type and amount of water containing the raw mix:

- within the range of $100-110^{\circ} \mathrm{C}$, the hardened composite system partially transforms into the pseudopyroplastic state and begins to deform with increasing volume;

- within the range of $130-147^{\circ} \mathrm{C}$, an intensive release of free and adsorbed water and intensive air entrainment of the sample mass occurs;

- at the temperature values above $147^{\circ} \mathrm{C}$, the removal of constitutional moisture, the completion of restructuring, physical and chemical transformations of composite systems are observed.

Based on the analysis of the thermographic data and the macrostructure of the samples obtained, it can be concluded that the greatest contribution to the formation of the product's structure with maximum homogeneity is made by the constitutional water, while removal of the excess adsorption moisture at the initial stages leads to the formation of large through pores and capillary channels in the raw mass. Therefore, the initial rare-glass composition should contain a minimum amount of free and adsorbed water.

As the efficient ways to reduce the free water's effects, the following ones can be recommended:
- direct thermal dehydration and transformation of soluble glass into xerogel (the basis of the present variant of the suggested technical solution);

- liquid granulation of composite systems (for example, in $\mathrm{Al}, \mathrm{Ca}, \mathrm{Zn}, \mathrm{Mg}$ chlorides solutions or their mixtures); - introducing of mineral fillers or chemical additives into the rare-glass composite system, which leads to the development of gelation processes.

The improved formulation of the raw mix preparing allows processing compositions in various ways with the formation of insulating materials of extended application: granular insulating filler (Fig. 5), materials for thermal insulation for the structures complicated in the form (Fig. 6), the plate and film-like types of insulating materials (Fig. 7) This task (depending on the purpose and features of the performed tasks) is solved by the capability of performing the final stages by means of several different ways of the products obtaining.

The use of the two stages procedure of the suggested renovation in the technology of preparing the porous thermal insulating materials determines: 1) the nature and the behavior peculiarities of the rare-glass composite systems components during the heat treatment, their strong adhesion manifestation related to most structural materials; 2) the necessity to solve the problem of easy workpieces removal from the formation molds; 3) the choice of the method for lining the internal surfaces of dismountable equipment molds; 4) thermophysical and chemical properties of the used lining material.

The features of the suggested project are:

- ease and availability of obtaining components and preparing the raw mix;

- formation of the raw mix directly at its "gaging" with soluble glass under the normal conditions;

- the thermal insulation method is fast;

- the possibility of easy formation and fragmentation of the raw workpieces, their inherent properties makes it possible to spread in time and space separate stages of thermal insulation: the stage of preparation, formation of granulate (possibly, in a specialized site); storage; transportation; technological packing in the working area complying with the increased resistance requirements to the heat transfer (possibly, in the construction site);

- processing of complicated working areas: selection of the raw mix cake thickness, the size and shape of the starting fragmented elements (depending on the target task and in order to provide more tight packing);

- the versatility of the thermal insulation method (based on the manifestation of significant adhesion ability of alkaline-silicate composite systems in relation to most structural materials: metals, ceramics, glass, wood);

- low shrinkage with the suggested formulation of the raw mix and the method of treatment; 


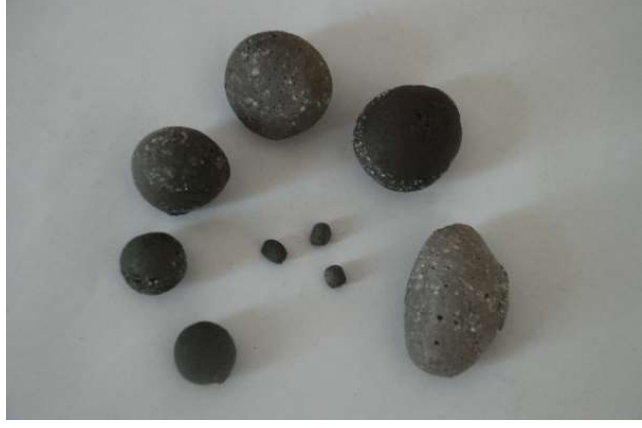

a)

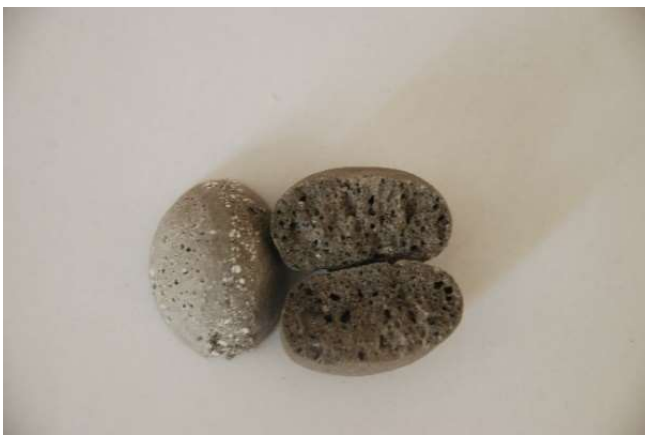

b)

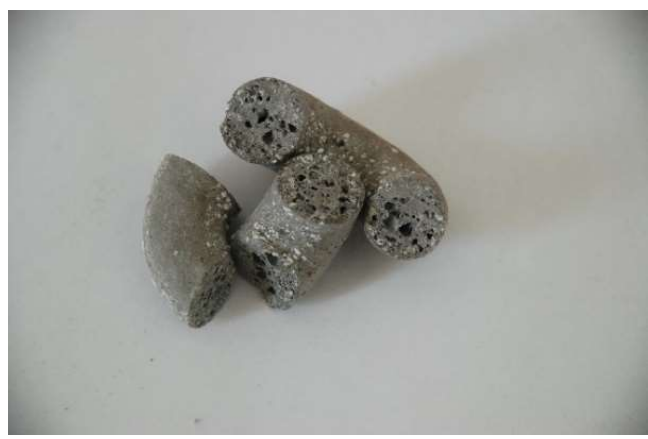

c)

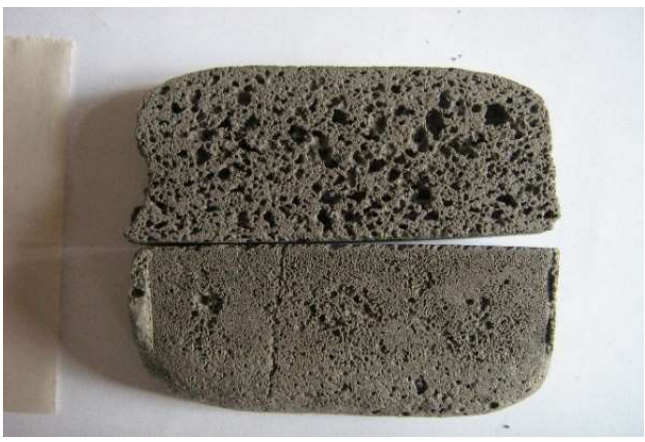

d)

Fig. 5. Illustration of the granular thermal insulating fillers' samples, obtained in the lined molds without limitation of formation volume:

a), b) cutting of iso-sized elements; c) cutting elements of plastic hardened raw cake of the set preformed thickness; d) of workpieces, formed in separate dismountable molds (new material, own photo)

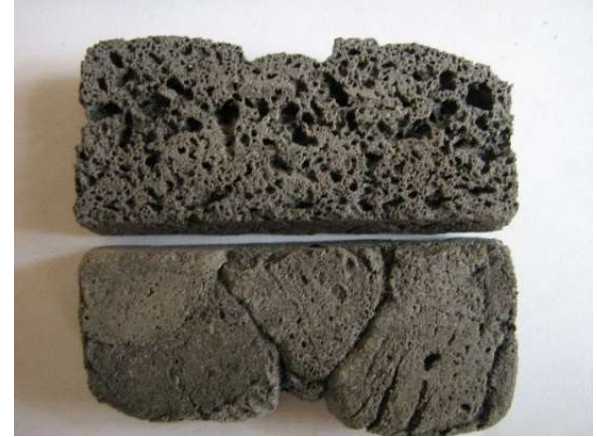

a)

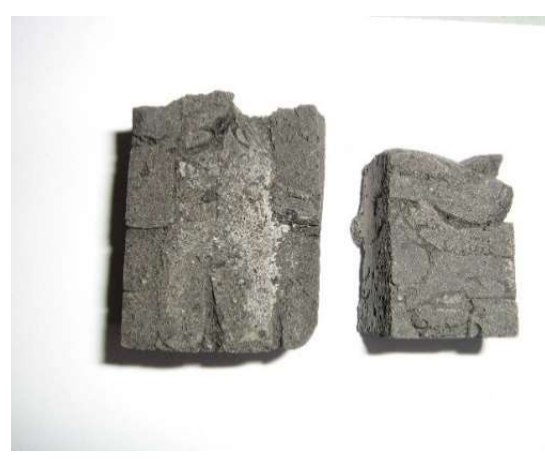

b)

Fig. 6. Illustration of fragments of thermal insulation zones sections in complicated form structures performed by the working zone filling with fragmented elements and the subsequent heat treatment in dismountable equipment of varying complexity:

a) - without limiting the free volume of formation; b) - with restriction of formation space (new material, own photo)

a)
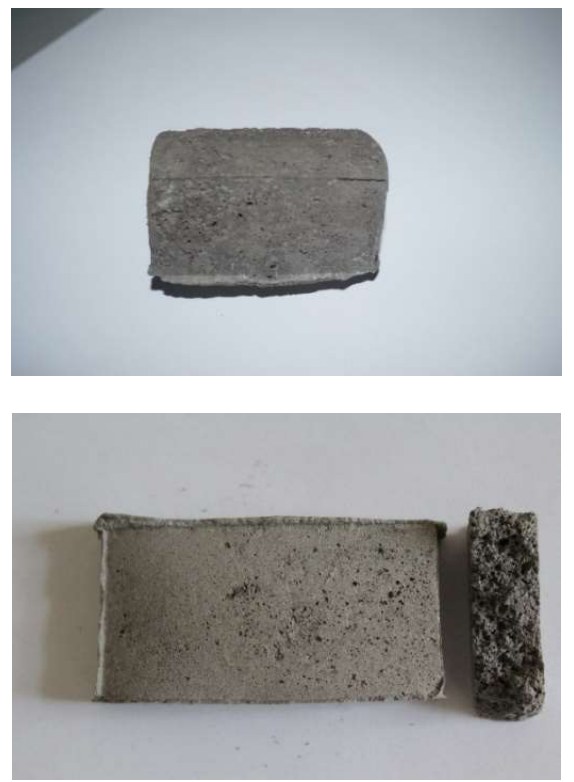

b)

Fig. 7. Illustration of the items fragments formed:

a) in the form of plates; $b$ ) in the form of films (new material, own photo) 
- indifference to most components and stability of the thermal insulation material properties, high thermal and chemical resistance, non-combustibility, ability to withstand significant temperatures;

- combination of the valuable properties set: low thermal conductivity factor, thermal stability, incombustibility, durability, low cost.

\section{Mathematical description of heat transfer through the body with a closed porosity}

For macro-porous body energy transfer will be characterized by the effective thermal conductivity coefficient or thermal resistance. If submit the heat energy as fluid, heat transfer description will be more simple. The heat flow through the porous body can be divided on the set of heat pipes, lateral boundaries are formed by the projection of the lateral pore surface with diameter $\mathrm{d}_{2}$. The pore is located in heat tube and has the dimensions, which are specified in Figure 8.

For steady flow, through each heat tube section per unit time the specific heat flux flows in the number

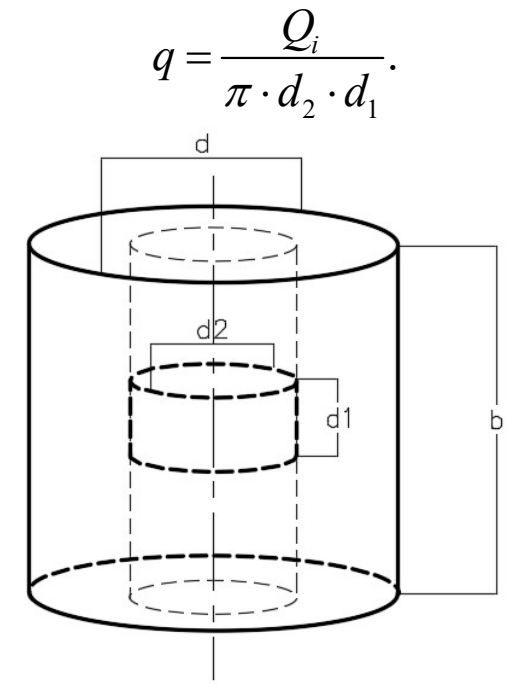

Fig. 8. The heat tube with the pore

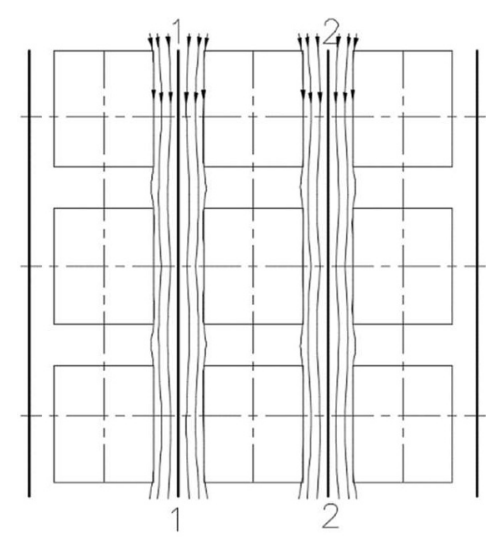

Fig. 9. Adiabatic lines in the porous material
On the figure 9 we can see heat flow lines through the porous structure. Heat flow lines near 1-1 and 2-2 lines are parallel and don't cross them. The lines 1-1 and 2-2 conditional can be taken as adiabatic planes. If consider heat flow limited by adiabatic planes 1-1 and 22 , which are directed along the heat flow between pores, we can find the heat flow channel between the pore and channel with conditional thickness d (Fig. 8). Let's consider the heat transfer in this channel only by the thermal conductivity of material.

The heat flow that will pass through this channel will be set following temperature difference at the ends of the channel

$$
\Delta T=\frac{q \cdot \Delta S \cdot b}{\lambda}
$$

where $\Delta S$ - thermal channel cross-sectional area through which heat is transferred only by the thermal conductivity of material; $\lambda$ - thermal conductivity coefficient of material; $b$ - channel length.

If substitute the heat flow, that passes through the heat pipe, in the temperature channel difference, we can obtain the minimum temperature at the end of heat channel

$$
T_{2}=T_{1}+\frac{Q_{i} \cdot \Delta S \cdot b}{\lambda \cdot \pi \cdot d_{2} \cdot d_{1}} . \quad \text { т }
$$

When $d_{1}=b$ (i.e. pore size equals to the thermal channel size) and we have one pore, it's easy to prove that

$$
\Delta S=\frac{\pi d^{2}(1-\Pi)}{\Pi}, \quad \text { т т }
$$

where $\Pi$ - porosity of material. For the common case the following relationship will be true

$$
\frac{b}{d_{1}}=\frac{n_{b}}{\Pi_{b}},
$$

where $n_{b}$ - pores number in the thermal channel; $\Pi_{b}-$ porosity of this channel. And also

$$
\Delta S=\frac{\pi\left(d^{2}-d_{2}^{2}\right)}{4} .
$$

The heat flux, which is flowing through the porous heat pipe, can be found via minimum temperature (minimum temperature difference) at the ends of the channel

$$
Q_{i}=\frac{\lambda \cdot \pi \cdot d_{2} \cdot \Pi_{b} \cdot \Delta T}{\Delta S \cdot n} .
$$

In this equation was highlighted $\phi_{i}=\frac{\Pi_{b}}{n_{b}}$.

The dimensionless value $\phi_{i}$ is a thermal permeability of thermal channel. In equation (5) the geometrical characteristic of thermal channel, which equals to the 
ratio of pore cross section line length to material surface area in the context of the pore

$$
\Gamma_{i}=\frac{\pi \cdot d_{2}}{\Delta S} .
$$

The dimension of this value is $\mathrm{m}^{-1}$. The bigger it is, the smaller difference between thermal channel and heat pipe. I.e. the greater will be this geometric characteristic, the smaller will be difference between $d_{2}$ and $d$.

The heat flux, which is flowing through the porous heat pipe, equals $Q_{i}=\lambda \cdot \phi_{i} \cdot \Gamma_{i} \cdot \Delta T$.

Minimum heat flow through the porous material will be equal to the sum of minimum thermal heat flows through the channels. Taking that the pores number and their size in the material thickness is constant, we get

$$
Q=\lambda \cdot \phi \cdot \Gamma \cdot \Delta T
$$

where $\phi-$ thermal permeability of porous material. So

$$
\lambda_{e f}=\lambda \cdot \phi \cdot \Gamma
$$

The geometrical characteristic of porous material

$$
\Gamma=\frac{\pi \sum d_{2}}{S-\sum \frac{\pi d_{2}{ }^{2}}{4}}
$$

where $\mathrm{S}$ - area of the material, to which heat was sent. The porous material geometric characteristic, for the pores plurality, can also be written in the integral form

$$
\Gamma=\frac{\int_{S} f\left(\mathrm{~d}_{2}\right) d S}{S-\iint_{S} f\left(\mathrm{~d}_{2}\right) d S},
$$

where $f\left(\mathrm{~d}_{2}\right)$ - function, that describes pores projection location on area $S+$ b on the area $S$. From the equation (7), the decrease of porous material thermal conductivity by the pores will depend on the $\phi \cdot \Gamma$

$$
\phi \cdot \Gamma=\frac{\Pi_{b}}{\overline{n_{b}}} \cdot \frac{\int_{S} f\left(\mathrm{~d}_{2}\right) d S}{S-\iint_{S} f\left(\mathrm{~d}_{2}\right) d S},
$$

where $\overline{n_{b}}$ - average pores number in the material thickness $b$, along the heat flux Q. So

$$
\lambda_{e f}=\lambda_{m} \cdot \frac{\Pi_{b}}{\overline{n_{b}}} \cdot \frac{\int_{S} f\left(\mathrm{~d}_{2}\right) d S}{S-\iint_{S} f\left(\mathrm{~d}_{2}\right) d S}
$$

\section{Conclusion}

1. Accelerated structure formation and high strength material provides chemical additives $\mathrm{NaCl}$ and $\mathrm{Na} 2 \mathrm{SO} 4$. The intensification of the processes of hydration and structure formation in ash-cement formulations with additives, including in its composition ion $\mathrm{Na}+$, is reflected in the rapid formation of structures with an earlier date grasp array. It should be noted that after mixing all the components, the temperature of the mixture was about $30{ }^{\circ} \mathrm{C}$, and after the swelling temperature rose to $60{ }^{\circ} \mathrm{C}$. Later mixture raised its temperature to $70-80{ }^{\circ} \mathrm{C}$. This in turn also leads to accelerated recruitment of early strength. Thus, the use of high-calcium ash and chemical additives allows you to adjust the properties of aerated concrete, at the stage of maturation of the array, and the final material.

2. The raw mix of silica-containing technogenic component - fly ash of thermal power plants - and the methods of preparing waterproof porous thermal insulating materials of extended application on its base according to the powder low-temperature technology has been developed using multifunctional properties of soluble glass as: a) a binding component; b) blowing agent; c) the raw mix hardening rate regulator. The physical and chemical, technological aspects of obtaining and using the suggested alkaline-silicate compositions have been considered.

3. The effective thermal conductivity coefficient for closed porous structure was mathematically derived for the first time. The coefficient of thermal permeability for porous structures was analytically found. Detected, that a thermal conductivity decrease in porous material by pores depends on the thermal permeability coefficient and geometrical characteristics of the porous structure.

\section{Acknowledgements}

Publication supported by the Polish Ministry of Science and Higher Education as a part of the program of activities disseminating science from the project „Organization of the First International Science Conference - Ecological and Environmental Engineering”, 26-29 June 2018, Kraków.

\section{References}

1. V.V. Kostin, The use of ashes and slag TPP in the production of concrete. - Novosibirsk: NSABU (2001).

2. S. Fei, L. Wang, J. Liu, M. Zeng Effect of heat treatment on silica aerogels prepared via ambient drying J. Mater. Sci. Technol. 23(3) 402-406 (2007).

3. A. M. Pavlenko, B. I. Basok, Regularities of BoilingUp of Emulsified Liquids/ Heat transfer research, 36(5) 419-424 (2005).

4. A.J.F. Chaves, D.R. Morales, Lastia quintera $R$. Recovery of genospheres and magnetite from coal burning power plant fly ash Trans. of Iron and Steel Inst. of Japan 27(7) 531- 538 (1987) 
5. Pavlenko, A., Koshlak, H., Design of the thermal insulation porous materials based on technogenic mineral fillers. EasternEuropean Journal of Enterprise Technologies 5/12 (89) 58-64 (2017)

6. Pavlenko, A., Koshlak, H., Production of porous material with projected thermophysical characteristics. Metallurgical and Mining Industry No. 1 118-122 (2015)

5. A. M. Pavlenko, B. I. Basok, A. A. Avramenko, Heat Conduction of a Multi-Layer Disperse Particle of Emulsion Heat transfer research, 36(1-2) 55-61 (2005)

6. V.V. Kostin, The use of ashes and slag TPP in the production of concrete. - Novosibirsk: NSABU 176 (2001)

7. A. M. Pavlenko, B. I. Basok, Kinetics of Water Evaporation from Emulsions/ Heat transfer research,
36(5) 425-430 (2005)

8. S. Fei, L. WANG, J. LIU, M, ZENG, Effect of heat treatment on silica aerogels prepared via ambient drying J. Mater. Sci. Technol. 23(3) 402 - 406 (2007) (in Chinese)

9. X. Wanga, Y. Jin, Z. Wang, Y. Nie, Q. Huang, Q. Wanga, Waste Manag .Development of lightweight aggregate from dry sewage sludge and coal ash 29 1330-1335 (2009)

10. S. Shaw, C.M.B. Henderson, B.U. Komanschek Dehydration/recrystallization mechanisms, energetics, and kinetics of hydrated calcium silicate minerals: an in situ TGA/DSC and synchrotron radiation SAXS/WAXS study Chemical Geology 167 (1-2) 141-159 (2000) 